\title{
Effect of Circuit Weight Training in C-Reactive Protein level of Obese Male Children
}

\author{
Rino Puji Dwi Sukmawan ${ }^{\mathrm{a}}$, Meisy Andriana ${ }^{\mathrm{b}, \text { Indrayuni Lukitra Wardhani }}{ }^{\mathrm{c}}$, Soenarnatalina \\ Melaniani ${ }^{\mathrm{d}}$. \\ sukmawanrino@gmail.com \\ aphysical Medicine and Rehabilitation Resident, Faculty of Medicines, Airlangga University, Surabaya 60286, Indonesia \\ ${ }^{\mathrm{bc}}$ Department of Physical Medicine and Rehabilitation, Faculty of Medicines, Airlangga University, Surabaya 60286, Indonesia \\ ${ }^{\mathrm{d}}$ Departement of Biostatistic and Population Study, Faculty of Public Health, Airlangga University, Surabaya 60286, Indonesia.
}

\begin{abstract}
Background: In the adolescent phase is a period of growth and development that requires more energy and nutrients, resulting in lifestyle changes that can lead to obesity. Circuit weight training (CWT) is a circuit training that aims to increase muscle strength and muscle endurance. C-Reactive Protein (CRP) is an indicator of systemic inflammation and increases in obesity.

Case: This study aimed to analyze the effect in obese male adolescents at SMAN 4 Surabaya. Subjects were 13 male adolescent age 14-18 years old, students of SMAN 4 Surabaya and obesity condition. Study subjects were intervened CWT 3 times in a week for 8 weeks. This study was conducted without calorie restriction. Analysis of the effect of CWT in CRP levels. Paired t test showed a significant CWT on CRP levels ( $\mathrm{p}=0.00)$. Effect Size CWT very strong to CRP..
\end{abstract}

Conclusion: CWT 3 times in a week for 8 weeks in obese male adolescents without calorie restriction can reduce CRP levels.

Keywords: Circuit Weight Training, C-Reactive Protein, adolescents, obesity.

\section{Introduction}

Energy balance in an individual can be effected by body weight and body composition as well as incoming and outgoing energy which will affect the body's physiology. Individuals who fail to maintain energy balance may experience weight gain (Hill, Wyatt and Peters, 2012). Increased body weight is correlated with an increase in the size and number of fat cells (Soegondo, 2009). In the adolescent phase, there is an acceleration of growth and development of the body that requires more energy and nutrients so that lifestyle changes can occur which can cause obesity problems (Barasi, 2007).

Global data in 2016 showed that there were $13 \%$ of adults aged 18 years and over who were obese and $39 \%$ were overweight (Seo, Noh and Kim, 2019). Based on the results of Riskesdas 2018, prevalence of overweight nutritional status (BMI/U) at the age of 5-12 years was $10.4 \%$ women and $11.2 \%$ men, aged $13-15$ years old was $11.7 \%$ female and $10.7 \%$ male, $11.4 \%$ female and $7.7 \%$ male 16-18 years old, while the prevalence of obesity at 5-12 years old was $7.7 \%$ female and $10.7 \%$ male, 4.3\% female and 5.3\% male, 13-15 years old 4.5\% female and 3.6\% male (Gurevich-Panigrahi et al., 2009; Kemenkes RI, 2019).

The increasing prevalence of obesity has become a major health problem in the age group of children and adolescents. Obesity is associated with a reduced life expectancy and an increased risk of cardiovascular disease, diabetes, and cancer (Engin, 2017). In general, the increased prevalence of obesity is caused by an increase in intake of high-calorie, high-fat foods, and a decrease in physical activity which is replaced by a sedentary lifestyle (Seo, Noh and Kim, 2019).

CWT is a circuit training that is carried out using weights and aims to increase muscle strength and muscle endurance, especially in major muscle groups (Klika and Jordan, 2013). In addition to increasing muscle strength, CWT is also beneficial for improving other components of physical fitness such as body composition, flexibility and cardiorespiratory-vascular endurance.

Weight loss is important in reducing inflammation. This can be achieved with a diet program, lifestyle changes, and a good exercise program. Exercise can reduce the inflammatory process by increasing protein synthesis and increasing fat burning (Michigan, Johnson and Master, 2011) and is associated with a decrease in CRP through regulatory mechanisms of IL-6 and TNF- cytokines released by adipocytes and hepatic cells (Campbell and Hausenblas, 2009; Kim, Li and Sim, 2020). The levels of inflammatory cytokines are inversely related to abdominal lipolysis and the expression of lipase-sensitive hormones so that a decrease in inflammatory cytokines is expected to increase fat burning and lose weight (Michigan, Johnson and Master, 2011).

Study on the effect of circuit weight training on CRP levels in obese adolescents is still limited, so the authors are interested in understanding the effect of circuit weight training on C-Reactive Protein levels in obese male adolescents. 
This study is an experimental study with before and after test analysis. Purpose of this study was to analyze the effect of CWT 3 times in a week for 8 weeks on the levels of CRP in obese male adolescents. This study was conducted without calorie restriction. The treatment given was in the form of strengthening exercises using the circuit weight training method.

Treatment and monitoring of CWT was carried out at the home of each subject. The study was conducted at 2021. Subjects in this study were 13 obese male adolescents aged 14-18 years old at State High School of Surabaya with obesity. This amount was added by $20 \%$ for the anticipation of dropping out, which was 2 people, so the number of subjects in this study was 14 people. The technique of taking the subject in this study was a consecutive sampling technique. The selection of SMA Negeri 4 Surabaya as the study subject was determined by purposive sampling.

The inclusion criteria for the study were male adolescents aged 14-18 years with good general medical conditions, ageappropriate Body Mass Index (BMI) (CDC BMI chart 2000) > P95, normal cognitive function, subjects stated that they were willing to participate in this study by signing consent form to be study subjects (informed consent). Subject's parents stated that they agreed to the subject's involvement by signing the consent form as a witness, the subject's arm length did not exceed the knee when the knee was flexed $45^{\circ}$ (upright position), cardiorespiratory-vascular endurance capacity $>6 \mathrm{METS}$ (measured by 6 minutes walking test), able to operate videocall and have their own cell phone.

The independent variable was resistance exercise study using the circuit weight training method. The dependent variables was levels of C - Reactive Protein. Confounding variables of daily food intake, daily physical activity.

\section{Results}

This study involved 13 students as the study sample. All male 14-18 years old with obesity. Normality test of data used Saphiro Wilk test, the distribution of the data showed a normal distribution on the variables of CRP. The variables were normally distributed so that parametric statistical tests were used with paired t-test.

Table 1. Normality test of subject before and after CWT

\begin{tabular}{lcccr}
\hline \multirow{2}{*}{ Variabel } & \multicolumn{2}{c}{ Before CWT } & \multicolumn{2}{c}{ After CWT } \\
\cline { 2 - 5 } & Mean \pm SD & p-value & Mean \pm SD & p-value \\
\hline C-Reactive Protein & $0,61 \pm 0,39$ & 0,142 & $0,33 \pm 0,26$ & 0,014 \\
\hline
\end{tabular}

Shapiro WIlk test are normal if p-value $>0,05$

The results of the Shapiro Wilk test on subjects in table 2 show the effect of CWT on normally distributed CRP levels. The average before CWT CRP was $0.61 \pm 0.39$ with a p-value of 0.142 and the average after CWT CRP was $0.33 \pm 0.26$ with a p-value of 0.014 .

Table 2. paired t test subject before and after CWT

\begin{tabular}{crrrr}
\hline \multicolumn{1}{c}{ Variable } & $\overline{\mathbf{x}}$ Before CWT & $\overline{\mathbf{x}}$ After CWT & Change & Significancy \\
\cline { 1 - 1 } C-Reactive Protein & 0,61 & 0,33 & $-0,28$ & 0,000 \\
\hline
\end{tabular}

Significant if $\mathrm{p}$-value $<0,05$

The results of the paired $t$ test in table 2 showed that there was effect of CWT on CRP levels $(p=0.000)$.

Table 3. Effect size test of subject before and after CWT

\begin{tabular}{lccc}
\hline Effect Size Test & Mean & SD & Cohen'd \\
\hline CRP before - CRP after & 0,284 & 0,199 & 1,427 \\
\hline
\end{tabular}

Effect size t test (Cohen's d) in table 3 showed very strong effect of CWT on CRP levels $(1,427)$. 


\section{Discussion}

This study explains that there is a very strong effect of CWT on CRP levels. CRP is an indicator of systemic inflammation and increases in obesity. This occurs due to an increase in pro-inflammatory cytokines, namely IL-6 which is derived from adipocytes (Kim, Li and Sim, 2020). CRP levels are known to increase after high-intensity acute exercise and to be lower after regular exercise. Increased levels of CRP can be caused by increased secretion of IL-6 which is an adipocytokine secreted by adipocytes. Increased IL-6 secretion will trigger an increase in lipolytic enzymes and insulin resistance which will increase CRP levels followed by a decrease in IL-6 levels, body weight, and body fat after regular exercise for 12 weeks (Kim, Li and Sim, 6371). Weight loss is important in reducing inflammation. This can be achieved with a good diet program, lifestyle changes, and an exercise program. Exercise can reduce the inflammatory process by increasing protein synthesis and increasing fat burning (Michigan, Johnson and Master, 2011).

CWT is an exercise that can reduce CRP levels when done regularly and continuously. The increase in muscle mass that plays a role in contractile activity is associated with an increased decrease in CRP levels. Previous study and theory explains that there is agreement with the results of this study regarding the significant effect of CWT with decreasing CRP.

\section{Conclusion}

There is very strong effect of CWT on C-Reactive Protein levels in obese male adolescents at SMAN 4 Surabaya.

\section{References}

Barasi, M. E. (2007) At a Glance: Ilmu Gizi. Jakarta: Erlangga.

Campbell, A. and Hausenblas, H. A. (2009) 'Effects of exercise interventions on body image: A meta-analysis', Journal of Health Psychology, 14(6), pp. 780-793. doi: 10.1177/1359105309338977.

Engin, A. (2017) 'The Definition and Prevalence of Obesity and Metabolic Syndrome', Advances in experimental medicine and biology. Adv Exp Med Biol, 960, pp. 1-17. doi: 10.1007/978-3-319-48382-5_1.

Gurevich-Panigrahi, T. et al. (2009) 'Obesity: pathophysiology and clinical management', Current medicinal chemistry. Curr Med Chem, 16(4), pp. 506-521. doi: 10.2174/092986709787315568.

Hill, J. O., Wyatt, H. R. and Peters, J. C. (2012) 'Obesity Energy Balance and Obesity How the Body Achieves Energy Balance', Circulation, 126, pp. 126-132. doi: 10.1161/CIRCULATIONAHA.111.087213.

Kemenkes RI (2019) Riset Kesehatan Dasar 2018. Jakarta.

Kim, J.-Y., Li, S. and Sim, Y.-J. (2020) 'The Effects of Circuit Weight Training and Weight Training on Aerobic Capacity and Health-related Fitness in Obese Male College Students', The Korean Journal of Growth and Development. Korean Society of Growth and Development, 28(1), pp. 23-28. doi: 10.34284/KJGD.2020.02.28.1.23.

Kim, J.-Y., Li, S. and Sim, Y.-J. (6371) 'The Effects of Circuit Weight Training and Weight Training on Aerobic Capacity and Health-related Fitness in Obese Male College Students', The Korean Journal of Growth and Development. KOREAN SOCIETY OF GROWTH AND DEVELOPMENT, 28(1), pp. 23-28. doi: 10.34284/KJGD.2020.02.28.1.23.

Klika, B. and Jordan, C. (2013) 'High-intensity circuit training using body weight: Maximum results with minimal investment', ACSM's Health and Fitness Journal, 17(3), pp. 8-13. doi: 10.1249/FIT.0B013E31828CB1E8.

Michigan, A., Johnson, T. V and Master, V. A. (2011) 'Review of the Relationship between C-Reactive Protein and Exercise', Mol Diag Ther, 15, pp. 265-275. doi: https://doi.org/10.1007/BF03256418.

Seo, Y. G., Noh, H. M. and Kim, S. Y. (2019) 'Weight loss effects of circuit training interventions: A systematic review and meta-analysis’, Obesity Reviews. John Wiley \& Sons, Ltd, 20(11), pp. 1642-1650. doi: 10.1111/OBR.12911.

Soegondo (2009) Obesitas. 5th edn. Edited by A. W. Sudoyo et al. Jakarta: Interna Publishing Pusat Penerbitan Ilmu Penyakit Dalam. 